\title{
Psychiatric training in two different EU countries: Denmark and the UK
}

\section{Denmark}

The undergraduate medical education in Denmark consists of six-and-a-half years of (mainly) academic studying. A combination of sabbatical years and latestarters pushed the average age of the medical candidate to 30 in 1998 . Well over $50 \%$ are women.

After graduation, there is a compulsory 18-month rotation as a house officer covering medicine, general surgery and general practice. Thereafter, the doctor wishing to specialise in psychiatry obtains a 12-month introduction post, learning 'the basics of the trade'. The trainee is then qualified to apply for a limited number of specialist rotations lasting four-and-a-half years. A central body of consultants distributes these posts by a standardised comparison of the applicants' curriculum vitae. Different aspects of their experience such as research, psychotherapy and teaching are each given a weighed number of points. Until recently this has been the hurdle to selection, but owing to the present shortage of doctors in Denmark the threshold for selection is very low. A block rotation includes one year of neurology, two years in a university psychiatric teaching post and 18 months as specialist registrar. Open and closed wards, liaison psychiatry and acute psychiatry are all included. An additional 18 months is required to proceed from specialist to the status of consultant. Departments are free to organise clinical training in their own way which can result in considerable differences in emphasis, that is, one department may favour a strictly biological approach, another may be psychodynamically oriented.

Theoretical training includes approximately 200 hours of centralised overview courses covering such topics as psychopathology, psychotherapy, forensic psychiatry etc. (Aggernaes \& Lindhardt, 1997). Education in psychotherapy consists of 60 one-hour sessions with patients linked with 60 hours of supervision and 60 hours of theory. Personal therapy is not mandatory. In the rotations there is usually no scheduled time for research nor for extra psychotherapeutic education. Such activities are welcomed but expected to be performed out of hours and often privately funded.

The total duration of training from medical graduation to psychiatric specialist is at best seven years, but in reality often much longer. There are no formal subspecialisations apart from general adult and child psychiatry.

It is worth noting that after graduation no further formal tests or examinations are incorporated in the career of a Danish doctor. The rise in the postgraduate education system has traditionally been determined by the informal evaluation by superiors and by the appli- cants' published research. The spirit has been one of individualism. Gaining clinical competence, theoretical knowledge and communication skills have largely been seen as a matter of personal initiative. Structured supervision has not been seen as a high priority. Junior doctors are often expected to work independently with little instruction, being expected to ask a senior doctor if in doubt.

In latter years, moves have been made to make education more streamlined and accountable. The department's responsibility for education has been formalised: Evaluation meetings are held six-monthly and evaluation forms are recorded by a regional training committee. Check-lists have to be met and each trainee has a personal tutor, although usually, there is no day to day supervision.

All trainees, training programmes and all departments involved must be approved by the National Board of Health. A British model inspector system reporting to the board has been introduced but has not as yet made any real impact in supervision of clinical education.

In spite of improvements, the Danish system seems to have serious shortcomings: The junior doctors complain of lack of real enthusiasm and commitment to education by their superiors, the consultants lament the working hours of their juniors which by law and working agreement can be as low as 37 hours per week including night shifts. According to many senior doctors the sparse attendance of trainees in daytime activities due to compulsory time-off after night shifts is detrimental for supervision and traditional bedside education. Both groups usually agree that years of cutbacks and tight funding have made for a hospital system where postgraduate education has been sidelined as a core function which can have dire future consequences.

\section{UK}

As an EU citizen, a Danish graduate can obtain General Medical Council registration and be appointed to a recognised senior house officer (SHO) training scheme with little problem. The notorious junior doctors' hours do however, come as a shock, to which is added the pressure of the membership exams. However, the pressures were, in our view, easily outweighed by the job satisfaction that followed; the organised supervision; weekly training courses for Part I and Part II and a general sense of the high academic standards of colleagues. Peers are generally younger compared with Denmark, most having graduated at the age of 24 (British Medical Association Cohort Study, 1995). 
Early retirement arrangements for doctors (including for older psychiatrists with mental health officer status) mean that many UK doctors retire well before the compulsory retirement age of 65 years, whereas in Denmark doctors often work up to their 70th birthday.

The close consultant supervision with all ward rounds supervised by the consultant, could be seen by some as hampering individual decision-making. Supervision, however, is clearly preferable for an apprenticeship like education at the SHO level.

After the MRCPsych Exams, the doctor (average age according to the Royal College 31 years), moves to specialist registrar (SpR) level for 3-4 years depending on the sub-speciality. This offers possibilities which are quite unique in Europe (forensic, general adult, children, psychotherapy etc). Sub-specialising can, unfortunately cause problems if the UK-educated psychiatrist wishes to convert his or her Certificate of Completion of Specialist Training to another EU country.

An SpR post also includes a weekly research day and a weekly special interest day (i.e. psychotherapy or administration). In addition, there are study leave periods for conferences and courses, which all in all, is a very generous deal for the trainee with rich opportunities to gain further qualifications.

\section{Discussion}

The UK postgraduate system puts greater emphasis on structuring the academic and clinical aspects of training. More time and educational resources are incorporated, membership exams ensure the standards of a common syllabus, and sub-specialisation is favoured. The Danish system leaves the trainee in a more individualistic position, he or she is generally older, is free from demanding exams, has much more spare time, and does not need to sub-specialise. Formalised training and supervision are, however, sparse compared with the UK. It is worth noting that the Danish trainee obtains more training in neurology than his or her UK counterpart (see Fig. 1).

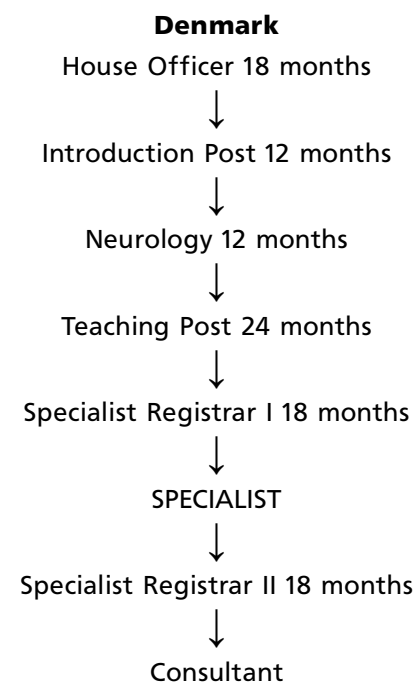

Some steps have been taken in order to harmonise the postgraduate psychiatric training of doctors in Europe (Caldicott, 1996; Cornwall \& Sheldon, 1997) such as setting up the European Trainees' Forum in 1992. Our personal experience tells us that there is still a very long way to go before trainees can move freely between EU countries with full recognition of their training. Further work on mutual minimum standards for patient care must remain a priority to the European Board of Psychiatry and the European Training Forum. A way forward would be implementation of a European exam system to secure a minimum of similarity of academic and clinical skills across the EU.

To achieve consensus I would suggest an international college system such as that in the UK for overall coordination and organisation of training and normsetting in the EU. The possibilities of such a superior organisation becoming dictatorial and absolute in its work, must, however, always be kept in mind. Specialist exams are demanding and tiresome for the trainees but essential to monitor levels of theoretical and practical knowledge, but whether the current UK Membership exam lives up to these requirements is another question.

Factors such as working conditions, working hours, exams, legal issues and financial considerations all play a role in choice of country but it is still our impression that it is the cultural and linguistic differences that deter most doctors from taking the step to apply for a post abroad. Psychiatry is traditionally a language-based speciality markedly influenced by social factors and, therefore, not seen ideal as a choice of speciality for doctors who wish to move freely between the European countries (Caldicott, 1996). This viewpoint is, together with the great difference in systems, probably responsible for the fact that relatively few trainees wish to move for a part of their training and even fewer stay as consultants. It would seem quite relevant to change this attitude since in the realm of psychiatry where we deal with basic human suffering due to maladaptive behaviour and alienation, it is likely to increase empathy if the psychiatrist is acquainted with the feeling of being different. What

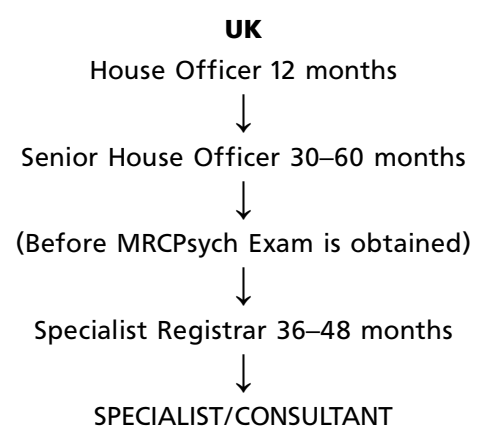

Fig. 1. Difference in emphasis on postgraduate exams. The UK from 1997, has had psychiatric membership exams at the end of the basic specialist training. There are no postgraduate exams in Denmark at all, but a 12-month post in neurology is mandatory in the training. 
better way to learn than living abroad for a period of your life?

The way forward towards further integration and harmonisation of the psychiatric training between the European countries would clearly be accelerated by more doctors having a multi-cultural experience in their training. This might be achieved by setting up more organised exchange schemes between EU countries for junior psychiatrists. However, language problems may always preclude this. It is pivotal of course that the, experience abroad is fully recognised in the trainee's home country. This would require considerably more inter-European similarity in the structure of the respective training schemes.

\section{References}

AGGERNAES, H. \& LINDARDT, A. (1997) Psychiatric training in Denmark. Journal of the European Archives of Psychiatry and Clinical Neuroscience, 247 (suppl. 1), 9.

psychiatry in Europe. Advances in PsychiatricTreatment, 2,141-

142. CORNWALL, P. \& SHELDON, L. (1997) The Fourth EuropeanTrainees' Forum. Psychiatric Bulletin, 21, 117

BRITISH MEDICAL ASSOCIATION

COHORT STUDY (1995) BMA Cohort Study of 1995 Medical Graduates. First Report - December 1995. London:

BMA.

CALDICOTT, F. (1996) Training in

MURRAY, R. (1995) European psychiatry; a force for the future. Psychiatric Bulletin, 19, 721-722.

WHITNEY, L. \& BRUCE, J. (1998)

Psychiatric training in Italy. Psychiatric Bulletin, 22, 762-763

*Lars K. Hansen, Specialist Registrar in Psychiatry, Anders F. Thomsen Senior House Officer in Psychiatry, Western Community Hospital, Walnut Grove, Millbrook, Southampton S016 4XE 